\title{
Robotic thyroidectomy versus endoscopic thyroidectomy: a meta-analysis
}

Shuang Lin ${ }^{1 \dagger}$, Zhi-Heng Chen ${ }^{1 \dagger}$, Hong-Gang Jiang ${ }^{1}$ and Ji-Ren Yu ${ }^{2^{*}}$

\begin{abstract}
Background: To conduct a meta-analysis to determine the relative merits of robotic thyroidectomy (RT) and endoscopic thyroidectomy (ET).

Methods: A literature search was performed to identify comparative studies reporting peri-operative outcomes for RT and ET. Pooled odds ratios (ORs) and weighted mean differences (WMDs) with 95\% confidence interval (95\% Cl) were calculated using either a fixed-effects or a random-effects model.

Results: Six studies matched the selection criteria, which reported on 2048 subjects, of whom 978 underwent RT and 1070 underwent ET. Comparing the outcomes of RT with ET, this meta-analysis indicated that RT was associated with more complications (WMD $=1.51,95 \% \mathrm{Cl} 1.18$ to 1.94$)$ and greater amount of drainage fluid $(\mathrm{WMD}=17.10,95 \% \mathrm{Cl} 5.69$ to 28.51). Meanwhile, operating time (WMD $=1.50,95 \% \mathrm{Cl}-39.59$ to 42.58$)$, conversion $(\mathrm{WMD}=0.63,95 \% \mathrm{Cl} 0.07$ to 6.17$)$, post-operative hospital stay (WMD $=-0.05 ; 95 \% \mathrm{Cl}-0.18$ to 0.08$)$, and the number of lymph nodes harvested (WMD $=0.62,95 \% \mathrm{Cl}-0.29$ to 1.53 ) were similar for both procedures.

Conclusion: The results of this meta-analysis indicated that RT is associated with an increased risk of complications and a greater amount of drainage fluid. Therefore, RT does not appear to have any advantage over ET. Further studies are required to confirm these results.
\end{abstract}

Keywords: Robotic thyroidectomy, Endoscopic thyroidectomy, Da Vinci robotic system, Meta-analysis

\section{Review}

\section{Introduction}

Since the first report of endoscopic thyroid lobectomy in 1997 [1], various endoscopic thyroid techniques or approaches have been described [2,3]. Many studies have reported several advantages of endoscopic thyroidectomy (ET) compared with open thyroidectomy, including better cosmetic results, a lower rate of post-operative complications, and better completion rate for surgery $[4,5]$. However, ET remains a technically challenging procedure. The two-dimensional visual representation and use of nonflexible endoscopic instruments can make it difficult to visualize the surgical field adequately and to manipulate instruments.

The Da Vinci robotic system was developed to improve the weak points of endoscopic surgery, and surgical

\footnotetext{
* Correspondence: yujirenzju@163.com

${ }^{\dagger}$ Equal contributors

${ }^{2}$ Department of Surgery, First Affiliated Hospital, Medical College, Zhejiang

University, Hangzhou 310003, Zhejiang Province, China

Full list of author information is available at the end of the article
}

robots have been successfully applied to a number of disciplines [6-8]. Recent studies have reported that robotic thyroidectomy (RT) is a feasible, safe, and effective method of performing such surgeries $[9,10]$, although most studies have been limited by small samples size and assessment at a single institution.

In this study, we aimed to determine the relative merits of RT and ET by performing a meta-analysis of studies comparing the two techniques.

\section{Methods}

Study selection

The Pubmed, EMBASE, Cochrane Library, Ovid, and Web of Science databases were searched systematically for all articles published in English before July 2012 that compared RT and ET. The terms used for the search were: 'robotic' and 'thyroidectomy'.

Reference lists of all retrieved articles were also manually searched for additional studies. Two reviewers independently extracted the data from each study. All relevant text,

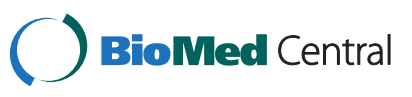




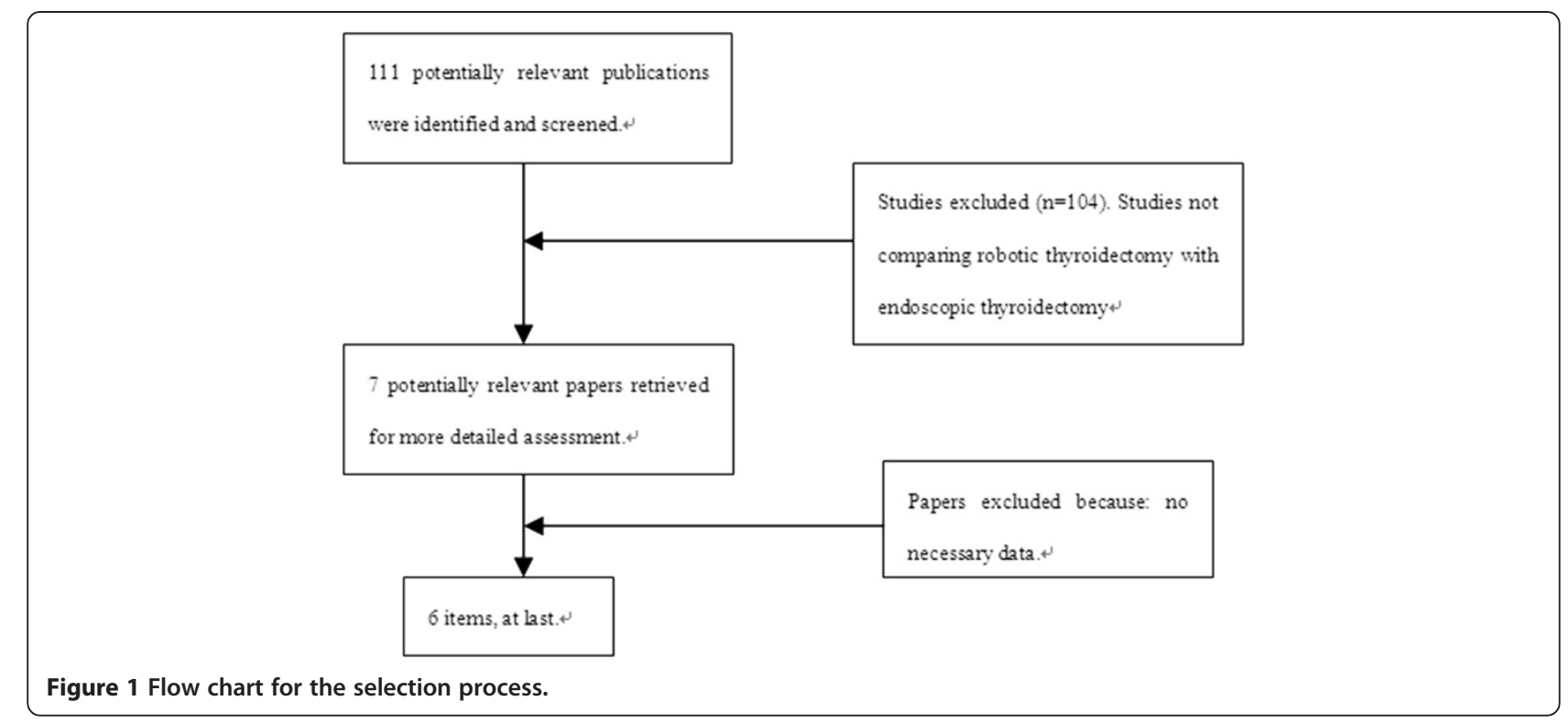

tables, and figures were reviewed for data extraction. Discrepancies between the two reviewers were resolved by discussion and consensus.

\section{Inclusion and exclusion criteria}

Only studies in the English language were considered for inclusion. In addition, each study had to fulfill the following criteria: 1) it compared the outcomes of RT and $\mathrm{ET}$, and 2) it reported on at least one of the outcome measures mentioned below. In cases where dual (or multiple) studies were reported by the same institution and/or authors, either the higher-quality or the most recent publication was included in the analysis.

Abstracts, letters, editorials and expert opinions, reviews without original data, case reports, and studies lacking control groups were excluded. The studies or data were also excluded when: 1) the outcomes and parameters of patients were not clearly reported (for example, with no clearly reported outcomes or standard deviations (SDs)); 2) it was impossible to extract the appropriate data from the published results; or 3) there was overlap between authors or centers in the published literature.

\section{Outcomes of interest and data extraction}

The following outcomes were used to compare the two operating techniques: 1) intra-operative data, which included operating time ( $\mathrm{min}$ ), and conversion; 2) postoperative data, which included complications, amount of drainage fluid $(\mathrm{ml})$, and post-operative hospital stay (days); and 3) pathologic details, which included number of lymph nodes harvested.

Two reviewers independently extracted the following parameters from each study: 1) first author and year of publication; 2) study population characteristics; 3) number of subjects who underwent each technique; and lastly, 4) intra-operative data, post-operative data, and pathologic details.

\section{Statistical analysis}

The meta-analysis was performed using the Review Manager (RevMan) software, (version 4.2.2; Cochrane IMS;

Table 1 Characteristics of included studies

\begin{tabular}{llllll}
\hline Study & Author & Year & Design & Group & $\begin{array}{l}\text { Patients in each } \\
\text { group, } \mathbf{n}\end{array}$ \\
\hline 1 & Yoo HH et al. & 2012 & NRCT & RT/ET & $46 / 165$ \\
\hline 2 & Tae K et al. & 2012 & NRCT & RT/ET & $113 / 105$ \\
\hline 3 & Lee S et al. & 2011 & NRCT & RT/ET & $580 / 570$ \\
\hline 5 & Lee J et al. & 2011 & NRCT & RT/ET & $163 / 96$ \\
\hline 6 & Lang BHH et al. & 2011 & NRCT & RT/ET & $7 / 39$ \\
\hline
\end{tabular}

ET, endoscopic thyroidectomy; NRCT, nonrandomized controlled trials; RT, robotic thyroidectomy. 
http://ims.cochrane.org). We analyzed dichotomous variables using estimation of odds ratio (OR) with 95\% confidence interval (CI) and continuous variables using weighted mean difference (WMD) with 95\% CI. The pooled effect was calculated using either a fixed-effects or a random-effects model. Heterogeneity between studies was evaluated using the $\chi^{2}$ and $\mathrm{I}^{2}$ tests, and we considered heterogeneity to be present if the $\mathrm{I}^{2}$ statistic was $>50 \% . P<0.05$ was considered significant.

\section{Results}

\section{Selection of trials}

The initial search strategy retrieved 111 publications, after screening all titles, abstracts, and full text. Six studies [11-16] met our entry criteria, and were retrieved for more detailed evaluation (Figure 1). All six studies were non-randomized controlled trials, and their characteristics are summarized in Table 1 . The total number of patients in all the trials was 2048. RT was performed on 978
Table 3 Post-operative histologic diagnosis

\begin{tabular}{llll}
\hline & Trial $^{\mathbf{a}}$ & Benign $^{\mathbf{b}}$ & Malignant $^{\mathbf{b}}$ \\
\hline 1 & Yoo HH et al. & $2: 17$ & $44: 148$ \\
\hline 2 & Tae K et al. & $21: 59$ & $92: 46$ \\
\hline 3 & Lee $\mathrm{S}$ et al. & - & $580: 570$ \\
\hline 4 & Lee J et al. & $11: 41$ & $152: 55$ \\
\hline 5 & Lang BHH et al. & $6: 35$ & $1: 4$ \\
\hline 6 & Kim WW et al. & - & $69: 95$ \\
\hline
\end{tabular}

an these studies, patients in the two groups were matched for operation time [11-14,16], conversion [11-16], complication [11-16], amount of drainage fluid $[11,12,14,16]$, length of post-operative hospital stay $[11-14,16]$, number of lymph nodes harvested [11-14,16].

${ }^{b}$ Benign/malignant: ratio of post-operative histology in robotic thyroidectomy or endoscopic thyroidectomy. Two studies did not have any benign tumors included.

patients and ET was on 1070 patients. The indications and exclusion criteria for surgery varied between the trials, and the post-operative histologic diagnosis are illustrated in Tables 2 and 3.

Table 2 Indication and exclusion for surgery

\begin{tabular}{|c|c|c|c|}
\hline & Trial & Indication for surgery & Exclusion criteria \\
\hline \multirow[t]{5}{*}{1} & Yoo HH et al. & Benign thyroid nodules & Nodule $>40 \mathrm{~mm}$ diameter \\
\hline & & Potentially thyroid nodules & Poorly differentiated thyroid cancer \\
\hline & & & Lateral lymph-node metastasis \\
\hline & & & Distant metastasis \\
\hline & & & Invasion to adjacent organs \\
\hline \multirow[t]{5}{*}{2} & Tae Ket al. & Benign thyroid nodules & Nodule $>50 \mathrm{~mm}$ diameter \\
\hline & & Follicular neoplasm & Nodule $>50 \mathrm{~mm}$ diameter \\
\hline & & Differentiated thyroid carcinoma & Nodule $>10 \mathrm{~mm}$ diameter \\
\hline & & & Cervical lymph-node metastasis \\
\hline & & & No single \\
\hline \multirow[t]{4}{*}{3} & Lee $\mathrm{S}$ et al. & Well-differentiated thyroid carcinoma & Multiple lateral cervical lymph-node metastases \\
\hline & & & Distant metastasis \\
\hline & & & Invasion to adjacent organs \\
\hline & & & Location in the thyroid dorsal area \\
\hline \multirow[t]{8}{*}{4} & Lee J et al. & Follicular neoplasm & Nodule $>50 \mathrm{~mm}$ diameter \\
\hline & & Differentiated thyroid carcinoma & Nodule $>30 \mathrm{~mm}$ diameter \\
\hline & & & Multiple lateral cervical lymph- metastases \\
\hline & & & Distant metastasis \\
\hline & & & Invasion to adjacent organs \\
\hline & & & Previous neck surgery \\
\hline & & & Severe Graves' disease \\
\hline & & & Location in the thyroid dorsal area \\
\hline \multirow[t]{2}{*}{5} & Lang BHH et al. & Benign thyroid nodules & Nodule $>40 \mathrm{~mm}$ diameter \\
\hline & & Potentially thyroid nodules & Nodule $>20 \mathrm{~mm}$ diameter \\
\hline \multirow[t]{5}{*}{6} & Kim WW et al. & Papillary thyroid microcarcinoma & Nodule $>10 \mathrm{~mm}$ diameter \\
\hline & & & Central cervical lymph- node metastases \\
\hline & & & Distant metastasis \\
\hline & & & Invasion to adjacent organs \\
\hline & & & Severe thyroiditis \\
\hline
\end{tabular}




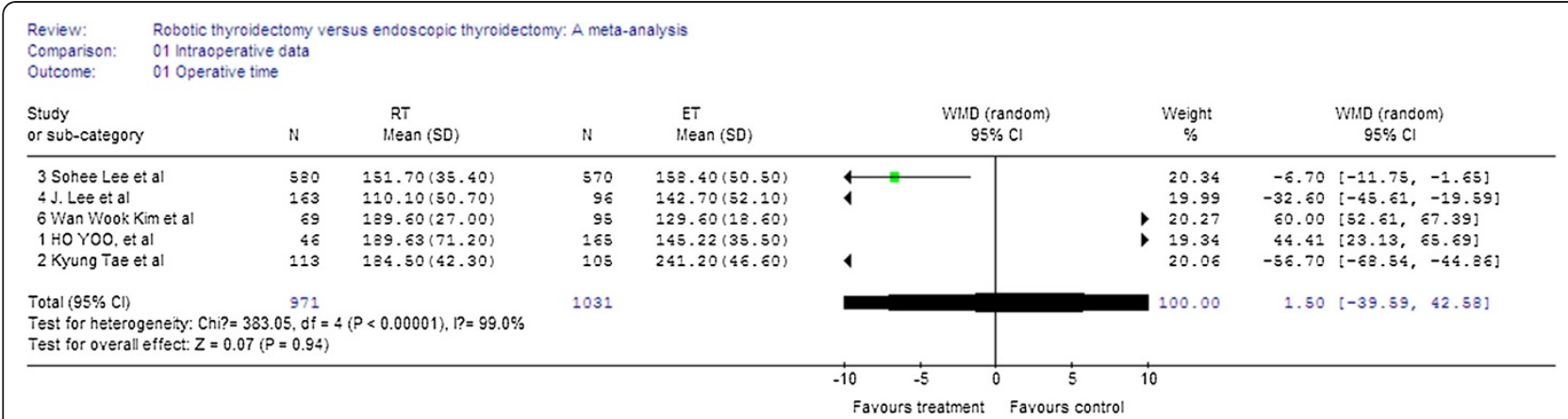

Figure 2 Forest plot displaying the results of the meta-analysis for operating time.

\section{Meta-analysis of intra-operative data}

In the five studies, there was no significant difference in the operating time between the RT and the ET groups (WMD $=1.50,95 \% \mathrm{CI}-39.59$ to 42.58 ). The random effects model was used because of the heterogeneity $\left(\mathrm{I}^{2}=99.0 \%\right.$ ) (Figure 2).

Six studies reported on conversion; there was no significant difference between the groups (WMD $=0.63$, $95 \%$ CI 0.07 to 6.17$)$. There was no significant heterogeneity between the studies $\left(\mathrm{I}^{2}=0 \%\right)$ (Figure 3 ).

\section{Meta-analysis of post-operative outcomes}

In the six studies, there was a significant difference in complications between the RT and the ET groups, with $\mathrm{RT}$ found to have more complications (WMD $=1.51$, 95\% CI 1.18 to 1.94$)$. There was no significant heterogeneity between the studies $\left(\mathrm{I}^{2}=0 \%\right)$ (Figure 4$)$.

Four studies reported on amount of drainage fluid Analysis of the pooled data showed that patients in the RT group had a greater amount of drainage fluid (WMD $=17.10$, 95\% CI 5.69 to 28.51) (Figure 5).

For the five studies, analysis of the pooled data showed that the two groups did not differ significantly in the length of post-operative hospital stay (WMD $=-0.05$; 95\% CI -0.18 to 0.08 ) (Figure 6).

\section{Meta-analysis of pathologic details}

In the five studies, there was no significant difference between the two groups in the number of lymph nodes harvested (WMD $=0.62,95 \% \mathrm{CI}-0.29$ to 1.53 ). The random-effects model was used because of the heterogeneity between the studies $\left(\mathrm{I}^{2}=89.4 \%\right)$ (Figure 7$)$.

\section{Discussion}

Meta-analysis can be used for both qualitative and quantitative evaluation of existing literature by comparing and integrating the results of different studies and taking into account variations in characteristics that could influence the overall estimate of the outcome of interest [17]. Although meta-analysis has been traditionally applied and was mostly confined to randomized controlled trials (RCTs), meta-analytical techniques using nonrandomized controlled trials (NRCTs) might be a good method for use in some clinical settings in which either the number or the sample size of the RCTs is insufficient $[18,19]$. To our knowledge, this is the first comprehensive meta-analysis comparing RT versus ET.

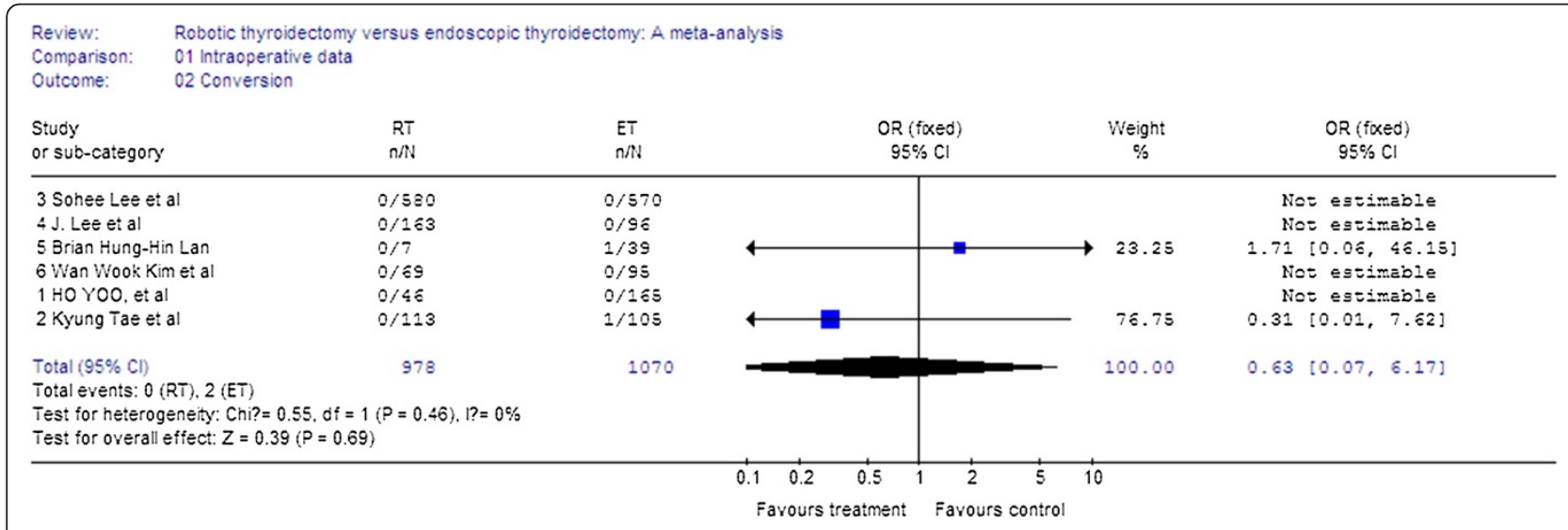

Figure 3 Forest plot displaying the results of the meta-analysis for conversion. 


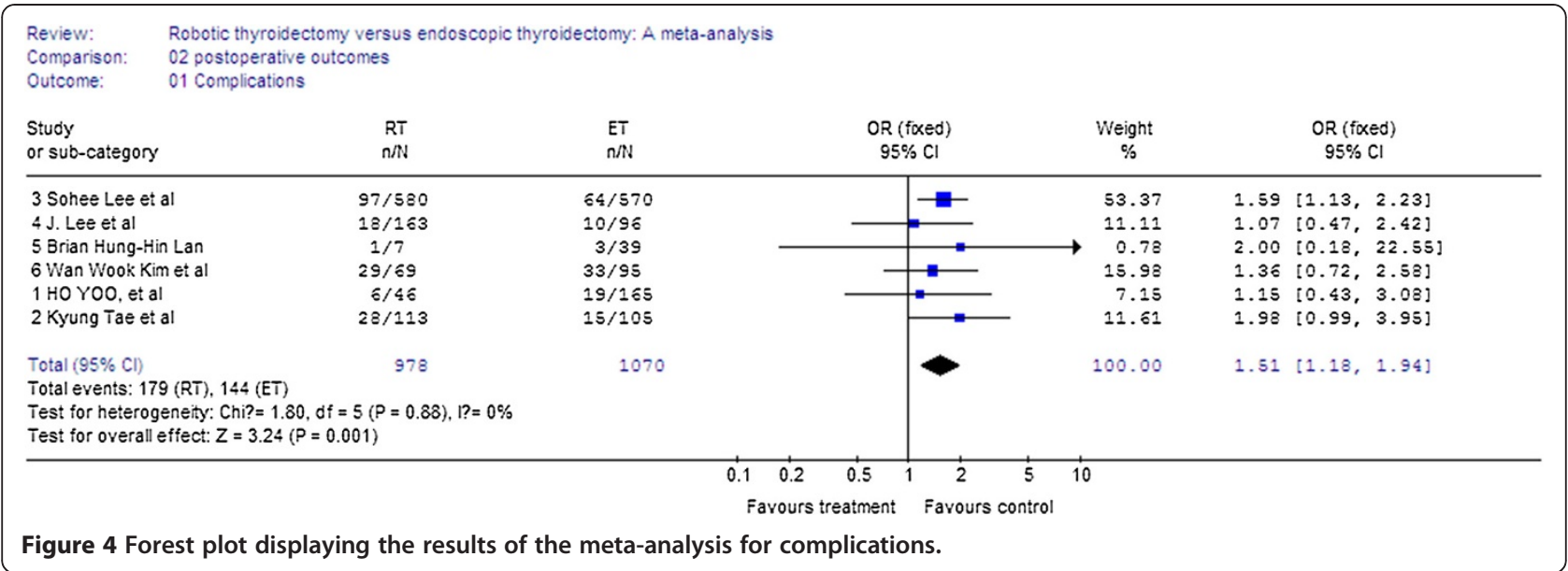

$\mathrm{RT}$ is often perceived as being more time-consuming, because of the additional set-up time required [20]. Operating times depend mainly on the experience and skill of the surgeon. In this meta-analysis, we found that there was no significant difference in operating time between RT and ET. This may be attributable to the shortened learning curve with RT, as it has been suggested that robotic systems make the technique easier to learn, even by relatively inexperienced endoscopic surgeons [6]. With increasing experience, set-up time gradually decreased, and the actual time may be shorter in RT. There was no significant difference in conversion rates between RT and ET.

Although RT offers a number of advantages over ET, including improvements in manual dexterity, ergonomics, and visualization, the results of the present metaanalysis suggest that there is no additional clinical benefit for RT over ET. The disadvantages of RT are a higher rate of complications and a greater amount of drainage fluid. It has been suggested that the characteristics of RT might reduce complications because, using the Da Vinci Surgical System, robotic arms are used for retraction and dissection, and their use has been found to reduce unnecessary procedures and to minimize iatrogenic tissue injury during retraction. Consequently, our result is difficult to explain, and more studies are needed before such a conclusion can be drawn. There was no difference in post-operative hospital stay between the two groups, implying that the time required for patients to resume daily activities might be similar between RT and ET.

Oncologic outcomes after thyroid cancer surgery are affected by the extent of lymph-node dissection and the completeness of thyroidectomy [21,22]. Some studies have concluded that more lymph nodes are harvested via $\mathrm{RT}$ compared with ET, and that the robotic method may improve the long-term prognosis in patients who undergo surgery for thyroid cancer $[13,14]$. In this analysis, we found no significant differences between RT and ET in the number of lymph nodes harvested; however, long-term follow-up evaluation is necessary to evaluate the exact oncologic outcomes of RT for thyroid cancer.

In the studied articles we found significant heterogeneity in operating time and number of lymph nodes harvested, which may be explained by the differences in personnel skills, extension of lymph-node dissection, and period of the learning curve. Because of this heterogeneity, we used a random-effects model in this metaanalysis.

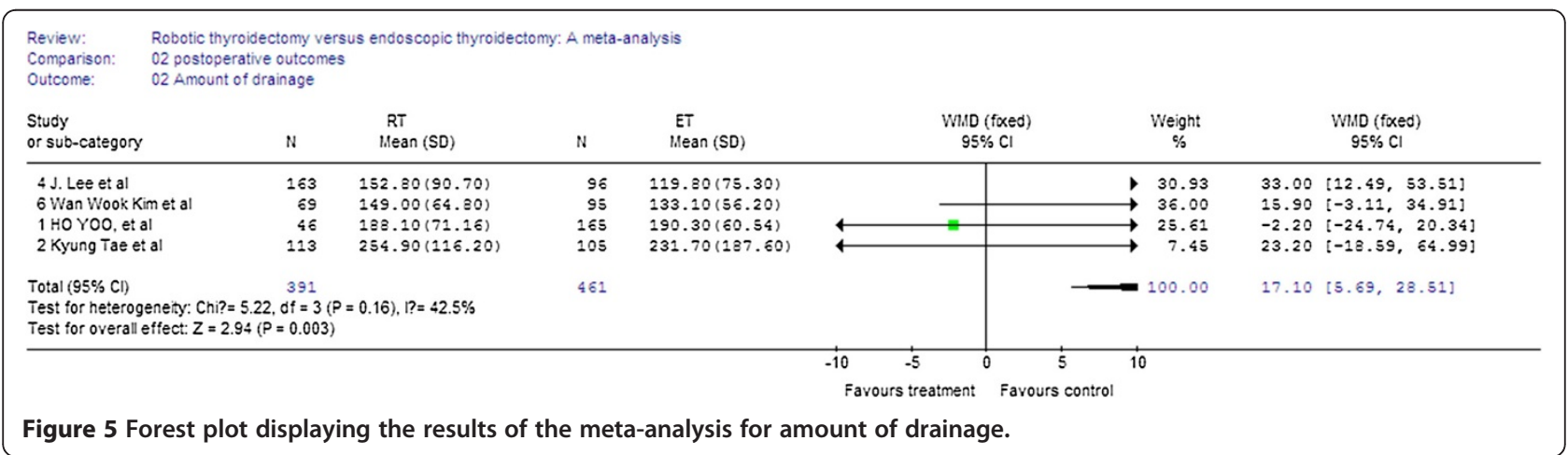




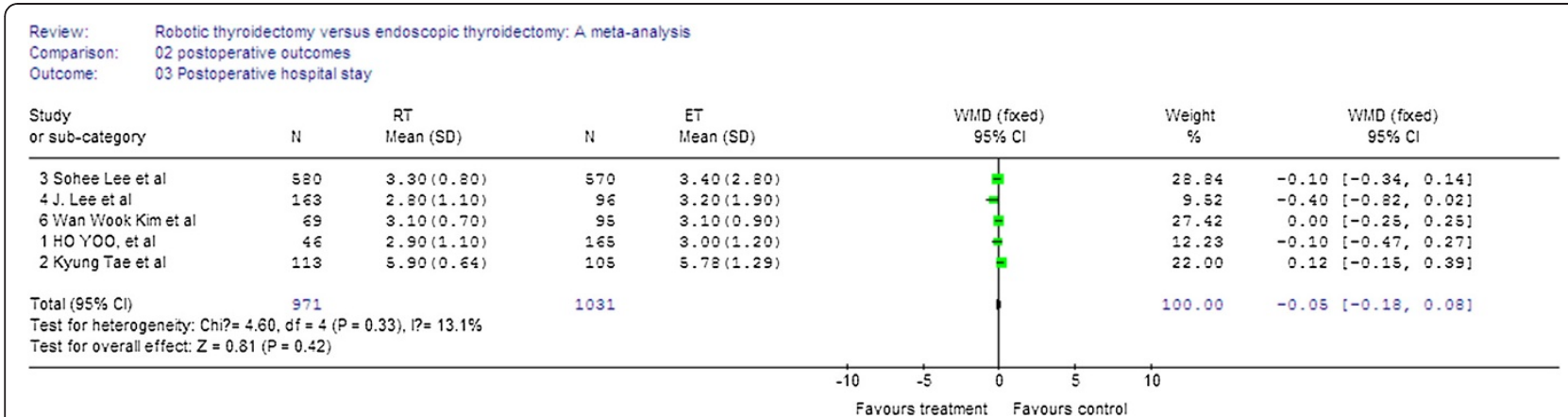

Figure 6 Forest plot displaying the results of the meta-analysis for post-operative hospital stay.

There are several limitations to this meta-analyis, and consequently, the results should be interpreted with caution. First, the data came from NRCTs, and the overall level of clinical evidence was low. It has been reported that NRCTs might either overestimate or underestimate the magnitude of the measured effect in an intervention study, regardless of quality scores [23]. However, Abrahama et al. found that metaanalyses carried out on well-designed NRCTs of surgical procedures were probably as accurate as those carried out on RCTs [24], and all six studies included in this study were NRCTs. Second, there was heterogeneity between the two groups because it was impossible to match the patient characteristics across all of the studies. We applied a random-effects model to take variation between studies into consideration, and we believe that the heterogeneity would have had very limited influence. Finally, it is possible that investigative groups might be more likely to report positive results, and that studies with significant outcomes are more likely to be published, therefore, potential publication bias might be present in our analysis.

\section{Conclusion}

The results of this meta-analysis of 2,048 patients showed that RT was associated with an increased complication rate and a greater amount of drainage fluid after surgery, thus RT does not appear have any advantage over ET. Further studies are required to confirm these results.

\section{Competing interests}

The authors declare that they have no competing interests.

\section{Authors' contributions}

YJR designed the study; CZH and YJR performed the literature search and retrieved data; LS and JHG collected the data; and LS and CZH performed the research and wrote the paper. All authors read and approved the final manuscript.

\section{Author details}

'Department of Oncological surgery, First Affiliated Hospital of Jiaxing University, Jiaxing 314000, Zhejiang Province, China. ${ }^{2}$ Department of Surgery, First Affiliated Hospital, Medical College, Zhejiang University, Hangzhou 310003, Zhejiang Province, China.

Received: 26 August 2012 Accepted: 24 October 2012

Published: 9 November 2012

\section{References}

1. Hüscher CS, Chiodini S, Napolitano C, Recher A: Endoscopic right thyroid lobectomy. Surg Endosc 1997, 11(8):877.

2. Jeong JJ, Kang SW, Yun JS, Sung TY, Lee SC, Lee YS, Nam KH, Chang HS, Chung WY, Park CS: Comparative study of endoscopic thyroidectomy versus conventional open thyroidectomy in papillary thyroid microcarcinoma (PTMC) patients. J Surg Oncol 2009, 100(6):477-480.

3. Ujiki MB, Sturgeon C, Denham D, Yip L, Angelos P: Minimally invasive video-assisted thyroidectomy for follicular neoplasm: is there an

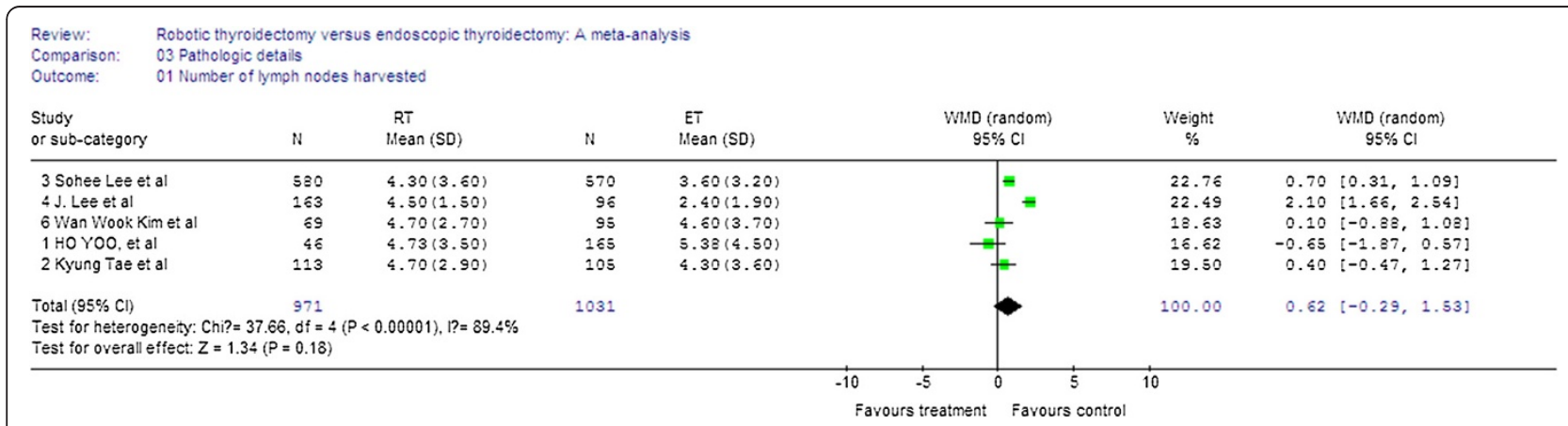

Figure 7 Forest plot displaying the results of the meta-analysis for number of lymph nodes harvested. 
advantage over conventional thyroidectomy? Ann Surg Oncol 2006, 13(2):182-186. Epub 2006 Jan 17.

4. Chen XD, Peng B, Gong RX, Wang L, Liao B, Li CL: Endoscopic thyroidectomy: an evidence-based research on feasibility, safety and clinical effectiveness. Chin Med J (Engl) 2008, 121(20):2088-2094.

5. Choi JY, Lee KE, Chung KW, Kim SW, Choe JH, Koo do H, Kim SJ, Lee J, Chung YS, Oh SK, Youn YK: Endoscopic thyroidectomy via bilateral axillo-breast approach (BABA): review of 512 cases in a single institute. Surg Endosc 2012, 26(4):948-955.

6. Lin S, Jiang HG, Chen ZH, Zhou SY, Liu XS, Yu JR: Meta-analysis of robotic and laparoscopic surgery for treatment of rectal cancer. World J Gastroenterol 2011, 17(47):5214-5220.

7. Maeso S, Reza M, Mayol JA, Blasco JA, Guerra M, Andradas E, Plana MN: Efficacy of the Da Vinci surgical system in abdominal surgery compared with that of laparoscopy: a systematic review and meta-analysis. Ann Surg 2010, 252(2):254-262.

8. Benmessaoud C, Kharrazi H, MacDorman KF: Facilitators and barriers to adopting robotic-assisted surgery: contextualizing the unified theory of acceptance and use of technology. PLoS One 2011, 6(1):e16395.

9. Kang SW, Park JH, Jeong JS, Lee CR, Park S, Lee SH, Jeong JJ, Nam KH, Chung WY, Park CS: Prospects of robotic thyroidectomy using a gasless, transaxillary approach for the management of thyroid carcinoma. Surg Laparosc Endosc Percutan Tech 2011, 21(4):223-229.

10. Lee KE, Koo do H, Kim SJ, Lee J, Park KS, Oh SK, Youn YK: Outcomes of 109 patients with papillary thyroid carcinoma who underwent robotic total thyroidectomy with central node dissection via the bilateral axillo-breast approach. Surgery 2010, 148(6):1207-1213.

11. Yoo H, Chae BJ, Park HS, Kim KH, Kim SH, Song BJ, Jung SS, Bae JS: Comparison of surgical outcomes between endoscopic and robotic thyroidectomy. J Surg Oncol 2012, 105(7):705-708. doi:10.1002/jso.22106. Epub 2011 Sep 27.

12. Tae K, Bae Ji Y, Hyeok Jeong J, Rae Kim K, Hwan Choi W, Hern Ahn Y: Comparative study of robotic versus endoscopic thyroidectomy by a gasless unilateral axillo-breast or axillary approach. Head Neck 2012. doi:10.1002/hed.22989.

13. Lee S, Ryu HR, Park JH, Kim KH, Kang SW, Jeong JJ, Nam KH, Chung WY, Park CS: Excellence in robotic thyroid surgery: a comparative study of robot-assisted versus conventional endoscopic thyroidectomy in papillary thyroid microcarcinoma patients. Ann Surg 2011, 253(6):1060-1066.

14. Lee J, Lee JH, Nah KY, Soh EY, Chung WY: Comparison of endoscopic and robotic thyroidectomy. Ann Surg Oncol 2011, 18(5):1439-1446.

15. Lang BH, Chow MP: A comparison of surgical outcomes between endoscopic and robotically assisted thyroidectomy: the authors' initial experience. Surg Endosc 2011, 25(5):1617-1623.

16. Kim WW, Kim JS, Hur SM, Kim SH, Lee SK, Choi JH, Kim S, Lee JE, Kim JH, Nam SJ, Yang JH, Choe JH: Is robotic surgery superior to endoscopic and open surgeries in thyroid cancer? World J Surg 2011, 35(4):779-784.

17. Aziz O, Constantinides V, Tekkis PP, Athanasiou T, Purkayastha S, Paraskeva P, Darzi AW, Heriot AG: Laparoscopic versus open surgery for rectal cancer: a meta-analysis. Ann Surg Oncol 2006, 13(3):413-424.

18. Mathurin P, Raynard B, Dharancy S, Kirzin S, Fallik D, Pruvot FR, Roumilhac D, Canva V, Paris JC, Chaput JC, Naveau S: Meta-analysis: evaluation of adjuvant therapy after curative liver resection for hepatocellular carcinoma. Aliment Pharmacol Ther 2003, 17(10):1247-1261.

19. Zhou Y, Zhao Y, Li B, Xu D, Yin Z, Xie F, Yang J: Meta-analysis of radiofrequency ablation versus hepatic resection for small hepatocellular carcinoma. BMC Gastroenterol 2010, 10:78.

20. Ng SS, Lee JF, Yiu RY, Li JC, Hon SS: Telerobotic-assisted laparoscopic abdominoperineal resection for low rectal cancer: report of the first case in Hong Kong and China with an updated literature review. World J Gastroenterol 2007, 13(17):2514-2518.

21. Mazzaferri EL: Papillary thyroid carcinoma: factors influencing prognosis and current therapy. Semin Oncol 1987, 14(3):315-332.

22. Bhattacharyya N: Surgical treatment of cervical nodal metastases in patients with papillary thyroid carcinoma. Arch Otolaryngol Head Neck Surg 2003, 129(10):1101-1104.

23. MacLehose RR, Reeves BC, Harvey IM, Sheldon TA, Russell IT, Black AM: A systematic review of comparisons of effect sizes derived from randomised and non-randomised studies. Health Technol Assess 2000, 4:1-154.

24. Abraham NS, Byrne CJ, Young JM, Solomon MJ: Meta-analysis of well-designed nonrandomized comparative studies of surgical procedures is as good as randomized controlled trials. J Clin Epidemio 2010, 63:238-245.

doi:10.1186/1477-7819-10-239

Cite this article as: Lin et al:: Robotic thyroidectomy versus endoscopic thyroidectomy: a meta-analysis. World Journal of Surgical Oncology 2012 10:239.

\section{Submit your next manuscript to BioMed Central and take full advantage of:}

- Convenient online submission

- Thorough peer review

- No space constraints or color figure charges

- Immediate publication on acceptance

- Inclusion in PubMed, CAS, Scopus and Google Scholar

- Research which is freely available for redistribution 